\title{
PENGARUH GAYA KEPEMIMPINAN DAN BUDAYA ORGANISASI TERHADAP KINERJA KARYAWAN DI DIVISI HUMAN CAPITAL MANAGEMENT PT BANK CENTRAL ASIA, TBK
}

\author{
Agnes Mega Kosasih \\ Program Studi Magister Manajemen Universitas Tarumanagara \\ Eko Harry Susanto \\ Program Studi Magister Manajemen Universitas Tarumanagara
}

\begin{abstract}
Along with the changing times and changes in consumer behavior in today's digital era, it encourages companies to adapt, not only from external factors but also from the company's internal factors. Existing leadership methods must be able to connect employees from different ages and backgrounds. In addition to leadership style, organizational culture is also an important consideration in today's business competition. This study aims to know and analyze simultaneously the influence of leadership style and organizational culture on the performance of employees in the Human Capital Management Division of PT Bank Central Asia, Tbk. This study uses quantitative analysis methods. Data collection was carried out with questionnaires distributed to employees of the Human Capital Management division at PT Bank Central Asia, Tbk. This study uses multiple linear analysis.
\end{abstract}

Keywords : Leadership Style, Organizational Culture, Employee Performance, Human Resources

Abstrak : Seiring dengan perkembangan jaman dan perubahan perilaku konsumen di era serba digital saat ini, mendorong perusahaan untuk terus beradaptasi terhadap perubahan yang terjadi dengan bijak bukan hanya melihat dari faktor eksternal saja namun juga faktor internal perusahaan itu sendiri. Metode kepemimpinan yang ada harus dapat menjembatani karyawan dari berbagai kalangan usia dan latar belakang yang berbeda-beda. Selain gaya kepemimpinan, budaya organisasi juga menjadi pertimbangan penting dalam persaingan bisnis saat ini. Penelitian ini bertujuan untuk mengetahui dan menganalisis secara simultan pengaruh gaya kepemimpinan dan budaya organisasi terhadap kinerja karyawan di Divisi Human Capital Management PT Bank Central Asia, Tbk. Penelitian ini menggunakan metode analisis kuantitatif. Pengumpulan data dilakukan dengan kuesioner yang disebarkan kepada karyawan divisi Human Capital Management di PT Bank Central Asia, Tbk. Penelitian ini menggunakan analisis linear berganda.

Kata kunci : Gaya Kepemimpinan, Budaya Organisasi, Kinerja Karyawan, Sumber Daya Manusia

\section{PENDAHULUAN \\ Latar Belakang}

Perbankan sebagai salah satu sektor perusahaan jasa, membutuhkan jaringan yang terintegrasi baik secara fisik maupun digital untuk melayani kebutuhan para nasabah yang merupakan salah satu fondasi utama dalam keunggulan bisnis perbankan. Seiring dengan pergeseran tren transaksi nasabah konvensional ke jaringan digital, perbankan dituntut lebih mempererat hubungan dengan para nasabahnya. Kunci layanan ada pada sumber daya manusianya, peningkatan kompetensi dalam memberikan solusi keuangan yang tuntas dan akurat merupakan fokus utama dalam layanan perbankan modern. 
Pengembangan sumber daya manusia dipengaruhi beberapa faktor antara lain dari budaya organisasi dan gaya kepemimpinan yang ada di perusahaan, apabila sumber daya manusia yang dimiliki dapat dikelola dengan baik tentunya sasaran bisnis akan dapat tercapai.

Budaya perusahaan yang baik akan mendorong semangat kerja bagi karyawan dan juga menciptakan lingkungan kerja yang kondusif, selain itu juga budaya perusahaan berperan penting dalam menyampaikan visi dan misi kepada karyawan.

Berdasarkan latar belakang di atas maka penulis tertarik untuk meneliti pengaruh gaya kepemimpinan dan budaya organisasi terhadap kinerja dengan memberikan judul "PENGARUH GAYA KEPEMIMPINAN DAN BUDAYA ORGANISASI TERHADAP KINERJA KARYAWAN DI DIVISI HUMAN CAPITAL MANAGEMENT PT BANK CENTRAL ASIA, TBK."

\section{Rumusan Masalah}

Sesuai latar belakang masalah yang telah dijelaskan sebelumnya mengenai adanya indikasi pengaruh gaya kepemimpinan dan budaya organisasi terhadap kinerja karyawan, maka dirumuskan masalah penelitian sebagai berikut :

1. Apakah terdapat pengaruh Gaya Kepemimpinan terhadap Kinerja karyawan di Divisi Human Capital Management PT Bank Central Asia, Tbk ?

2. Apakah terdapat pengaruh Budaya Organisasi terhadap Kinerja karyawan di Divisi Human Capital Management PT Bank Central Asia, Tbk?

3. Apakah terdapat pengaruh Gaya Kepemimpinan dan Budaya Organisasi secara simultan terhadap Kinerja Karyawan di Divisi Human Capital Management PT Bank Central Asia, Tbk?

\section{METODE PENELITIAN}

Analisis kuantitatif yang dilakukan oleh penulis dalam penelitian ini adalah analisis regresi linier berganda antara Gaya Kepemimpinan dan Budaya Organisasi terhadap Kinerja Karyawan, analisis ini digunakan untuk mengetahui pola hubungan serta pengaruh suatu hal atau variabel yang dipengaruhi oleh lebih dari satu variabel lain. Untuk memperoleh hasil yang lebih akurat dan mempermudah pengolahan data, digunakan statistical program for social science (SPSS).

Menurut tujuannya, penelitian yang digunakan pada penelitian ini adalah penelitian murni. Menurut Mudrajad (2013:5), "Penelitian murni merupakan penelitian yang meliputi pengembangan ilmu pengetahuan". Sedangkan berdasarkan pendekatannya penelitian ini menggunakan pendekatan survey yang dilakukan pada populasi besar maupun kecil, tetapi data yang dipelajari adalah data dari sampel yang diambil dari populasi tersebut, sehingga ditemukan kejadian-kejadian relatif, distribusi, dan hubungan-hubungan antar variabel. Berdasarkan jenis datanya, jenis data yang digunakan pada penelitian ini adalah kuantitatif, menurut Mudrajad (2013:145) yaitu data yang diukur dalam suatu skala numerik (angka).

Metode yang digunakan dalam pengambilan sampel adalah metode non probability sampling, yang berarti pengambilan sampel tidak memberi peluang kesempatan sama bagi setiap unsur atau anggota populasi untuk dipilih menjadi sampel karena pertimbangan tertentu.

Sedangkan teknik pengambilan yang digunakan adalah teknik purposive sampling, yaitu teknik penentuan sampel yang digunakan untuk tujuan tertentu (Sugiyono, 2008), sehingga data yang diperoleh lebih representative.

\section{HASIL DAN PEMBAHASAN}

Hasil analisis pengujian data validitas dan reliabilitas menunjukkan nilai $r$ hitung $>\mathrm{r}$ tabel $(0,1743)$ (corrected item-total correlation) sehingga data yang diperoleh dari penelitian menunjukkan bahwa setiap butir soal pada masing-masing variabel dinyatakan valid dan dikatakan reliabel karena nilai Alpha Cronbach $\geq 0,7$. 
Hal ini menunjukkan bahwa pernyataan-pernyataan yang terdapat di dalam angket dapat dijadikan pengukur data yang sesuai, maka dilakukan uji reliabilitas untuk menguji kekonsistenan jawaban. Berdasarkan pernyataan yang ada dalam angket menunjukkan bahwa jawaban responden konsisten sehingga penelitian ini layak untuk di lanjutkan ke analisis selanjutnya.

Hasil dari pengujian asumsi klasik yang dilakukan, yaitu uji multikolinearitas, uji heteroskedastisitas, dan uji normalitas mendapatkan hasil yang baik dimana tidak terjadi multikolinearitas, heteroskedastisitas dan data berdistribusi normal.

Pada pengujian regresi linier berganda didapatkan hasil tabel seperti dibawah ini :

Tabel 1. Regresi Linier Berganda

\begin{tabular}{|c|c|c|c|c|c|c|c|}
\hline \multirow{2}{*}{ Model } & \multicolumn{2}{|c|}{$\begin{array}{l}\text { Unstandardized } \\
\text { Coefficients }\end{array}$} & \multirow{2}{*}{$\begin{array}{l}\text { Standardized } \\
\text { Coefficients }\end{array}$} & \multirow{2}{*}{$\mathrm{t}$} & \multirow{2}{*}{ Sig. } & \multicolumn{2}{|c|}{$\begin{array}{l}\text { Collinearity } \\
\text { Statistics }\end{array}$} \\
\hline & B & $\begin{array}{l}\text { Std. } \\
\text { Error }\end{array}$ & & & & Tolerance & VIF \\
\hline (Constant) & 4,645 & 1,571 & & 2,956 & 0,004 & & \\
\hline $\begin{array}{ll}\text { Gaya } \\
\text { Kepemimpinan }\end{array}$ & 0,537 & 0,058 & 0,589 & 9,193 & 0 & 0,472 & 2,118 \\
\hline Budaya Organisasi & 0,344 & 0,065 & 0,34 & 5,311 & 0 & 0,472 & 2,118 \\
\hline
\end{tabular}

a. Dependent Variable: Kinerja Karyawan

Sumber : Hasil Pengolahan Data SPSS berikut:

Dari tabel dapat diketahui bahwa persamaan regresi yang dihasilkan adalah sebagai

$$
\mathrm{Y}=4,645+0,537 \mathrm{X} 1+0,344 \mathrm{X} 2+\mathrm{e}
$$

Berdasarkan analisa nilai koefisien regresi tersebut maka dapat disimpulkan bahwa

1. Nilai variabel dependen Kinerja Karyawan (Y) dapat dilihat dari nilai konstantanya sebesar 4,645 dengan catatan jika variabel independen Gaya Kepemimpinan (X1) dan Budaya Organisasi (X2) tidak mempengaruhi variabel dependen Kinerja Karyawan (Y).

2. Pengaruh variabel independen Gaya Kepemimpinan (X1) terhadap (Y) Kinerja Karyawan apabila dilihat dari besarnya koefisien regresi 0,537 maka dapat diartikan bahwa setiap perubahan variabel Gaya Kepemimpinan (X1) sebesar satu satuan maka variabel Kinerja Karyawan (Y) akan meningkat sebesar 0,537 dengan catatan variabel Budaya Organisasi (X2) tetap.

3. Pengaruh variabel independen Budaya Organisasi (X2) terhadap (Y) Kinerja Karyawan apabila dilihat dari besarnya koefisien regresi 0,344 maka dapat diartikan bahwa setiap perubahan variabel Lingkungan Kerja (X2) sebesar satu satuan maka variabel Kinerja Karyawan (Y) akan meningkat sebesar sebesar 0,344 dengan catatan variabel Gaya Kepemimpinan (X1) tetap.

Penulis juga melakukan pengujian hipotesis secara simultan dan parsial dengan menggunakan Uji F (simultan) dan Uji t (parsial). Berikut tabel yang dihasilkan :

\section{Pengujian Hipotesis secara Simultan (Uji F)}

- H0 : $\beta 1, \beta 2=0$ (Gaya Kepemimpinan (X1) dan Budaya Organisasi (X2) secara serentak atau bersama sama tidak berpengaruh terhadap Kinerja Karyawan (Y))

- $\mathrm{H} 1: \beta 1, \beta 2 \neq 0$ (Gaya Kepemimpinan (X1) dan Budaya Organisasi (X2) secara serentak atau bersama sama berpengaruh terhadap Kinerja Karyawan (Y)) 
Tabel 2. Uji F

\begin{tabular}{|c|c|c|c|c|c|}
\hline Model & Sum of Squares & $\mathrm{df}$ & Mean Square & $\mathrm{F}$ & Sig. \\
\hline Regression & 1338,637 & 2 & 669,319 & 194,478 &, $000^{\mathrm{b}}$ \\
\hline 1 Residual & 437,086 & 127 & 3,442 & & \\
\hline Total & 1775,723 & 129 & & & \\
\hline
\end{tabular}

a. Dependent Variable: Kinerja Karyawan

b. Predictors: (Constant), Budaya Organisasi, Gaya Kepemimpinan

Sumber : Hasil Pengolahan Data SPSS

Kesimpulan :

Karena nilai signifikansi $0,000<0,05$ atau nilai $f$ tabel $>\mathrm{f}$ hitung $(194,478>3,068)$ maka H0 ditolak dan H1 diterima. Hal ini menunjukkan bahwa Gaya Kepemimpinan (X1) dan Budaya Organisasi (X2) secara serentak atau bersama sama berpengaruh terhadap Kinerja Karyawan (Y).

\section{Pengujian Hipotesis secara Parsial (Uji t)}

- Ho : $\beta 1=0$ (secara parsial variabel Gaya Kepemimpinan (X1) tidak berpengaruh terhadap Kinerja Karyawan (Y)).

- $\mathrm{H} 1: \beta 1 \neq 0$ (secara parsial variabel Gaya Kepemimpinan (X1) berpengaruh terhadap Kinerja Karyawan (Y)).

- Ho : $\beta 1=0$ (secara parsial variabel Budaya Organisasi (X2) tidak berpengaruh terhadap Kinerja Karyawan (Y)).

- H1 : $\beta 1 \neq 0 \quad$ (secara parsial variabel Budaya Organisasi (X2) berpengaruh terhadap Kinerja Karyawan (Y)).

Tabel 3. Uji t

\begin{tabular}{|c|c|c|c|c|c|c|c|}
\hline \multirow{2}{*}{ Model } & \multicolumn{2}{|c|}{$\begin{array}{l}\text { Unstandardized } \\
\text { Coefficients }\end{array}$} & \multirow{2}{*}{$\begin{array}{l}\text { Standardized } \\
\text { Coefficients }\end{array}$} & \multirow{2}{*}{$\mathrm{t}$} & \multirow{2}{*}{ Sig. } & \multicolumn{2}{|c|}{$\begin{array}{l}\text { Collinearity } \\
\text { Statistics }\end{array}$} \\
\hline & $\mathrm{B}$ & $\begin{array}{l}\text { Std. } \\
\text { Error }\end{array}$ & & & & Tolerance & VIF \\
\hline (Constant) & 4,645 & 1,571 & & 2,956 & 0,004 & & \\
\hline $\begin{array}{ll}1 & \text { Gaya } \\
\text { Kepemimpinan }\end{array}$ & 0,537 & 0,058 & 0,589 & 9,193 & 0 & 0,472 & 2,118 \\
\hline Budaya Organisasi & 0,344 & 0,065 & 0,34 & 5,311 & 0 & 0,472 & 2,118 \\
\hline
\end{tabular}

a. Dependent Variable: Kinerja Karyawan

Sumber : Hasil Pengolahan Data SPSS

Kesimpulan :

- Karena nilai signifikansi $0,000<0,05$ atau nilai t hitung $>\mathrm{t}$ tabel $(9,193>1,657)$ maka H0 ditolak dan H1 diterima. Hal ini menunjukkan bahwa secara parsial variabel Gaya Kepemimpinan (X1) berpengaruh signifikan terhadap Kinerja Karyawan (Y).

- Karena nilai signifikansi $0,000<0,05$ atau nilai $t$ hitung $>t$ tabel $(5,311>1,657)$ maka $\mathrm{H} 0$ ditolak dan $\mathrm{H} 1$ diterima. Hal ini menunjukkan bahwa secara parsial variabel Budaya Organisasi (X2) berpengaruh signifikan terhadap Kinerja Karyawan (Y). 


\section{Koefisien Korelasi (R) dan Koefisien Determinasi (R2)}

Tabel 4. Koefisien Korelasi \& Determinasi

\begin{tabular}{|l|l|l|lr|l|l|}
\hline Model & $\mathrm{R}$ & $\begin{array}{l}\mathrm{R} \\
\text { Square }\end{array}$ & $\begin{array}{l}\text { Adjusted } \\
\text { Square }\end{array}$ & $\begin{array}{l}\text { Std. Error of the } \\
\text { Estimate }\end{array}$ & $\begin{array}{l}\text { Durbin- } \\
\text { Watson }\end{array}$ \\
\hline 1 &, $868^{\mathrm{a}}$ & 0,754 & 0,75 & 1,85516 & 2,078 \\
\hline
\end{tabular}

a. Predictors: (Constant), Budaya Organisasi, Gaya Kepemimpinan

b. Dependent Variable: Kinerja Karyawan

Sumber : Hasil Pengolahan Data SPSS

Dari tabel diketahui bahwa nilai koefisien korelasi berganda (R), yaitu korelasi antara dua atau lebih variabel independen (Gaya Kepemimpinan (X1) dan Budaya Organisasi (X2) terhadap variabel dependen (Kinerja Karyawan (Y) sebesar 0,868. Hal ini berarti terdapat hubungan yang sangat kuat.

Nilai koefisien determinasi berganda (R-square) adalah 0,754 atau $75,4 \%$ nilai ini menunjukkan bahwa 75,4\% Kinerja Karyawan (Y) dipengaruhi oleh Gaya Kepemimpinan (X1) dan Budaya Organisasi (X2) dan sisanya 24,5\% dipengaruhi oleh variabel lain diluar penelitian.

\section{KESIMPULAN DAN SARAN}

Berdasarkan hasil analisis data dan pembahasan dapat disimpulkan sebagai berikut:

1. Terdapat pengaruh yang signifikan antara Gaya Kepemimpinan terhadap Kinerja Karyawan

2. Terdapat pengaruh yang signifikan antara Budaya Organisasi terhadap Kinerja Karyawan

3. Terdapat pengaruh yang signifikan secara bersamaan antara Budaya Organisasi dan Gaya Kepemimpinan terhadap Kinerja Karyawan

Berdasarkan analisis data dan kesimpulan yang telah dikemukakan, maka saran yang disampaikan dalam penelitian ini adalah :

1. Bagi Perusahaan diharapkan dapat menciptakan program coaching yang lebih subjektif agar kinerja karyawan dapat ditingkatkan dan menciptakan budaya organisasi yang kuat antara atasan dan bawahan agar kinerja karyawan dapat meningkat lebih baik.

2. Bagi peneliti lain, penulis menyarankan memperluas cakupan responden yang ada agar dapat menghasilkan data yang lebih akurat untuk keseluruhan perusahaan dan menambah variabel-variabel lainnya yang dapat mempengaruhi kinerja karyawan.

3. Bagi pembaca, diharapkan tidak terpaku pada satu macam penelitian untuk menarik kesimpulan tentang faktor-faktor yang mempengaruhi kinerja karyawan dan sedapat mungkin membaca beberapa penelitian untuk menambah wawasan

\section{REFERENSI}

Alhusin, Syahri. (2003). Aplikasi Statistik Dengan SPSS.10 for Windows. Yogyakarta: Penerbit Alhusin, Syahri. (2003). Aplikasi Statistik Dengan SPSS.10 for Windows. Yogyakarta: Penerbit Graha Ilmu.

Al-Sada, Maryam. (2017). "Influence of organizational culture and leadership style on employee satisfaction, commitment and motivation in the educational sector in Qatar". EuroMed Journal of Business, 12 (2), 163-188.

Guritno dan Waridin. (2005). Pengaruh Persepsi Karyawan Mengenai Perilaku Kepemimpinan, Kepuasan Kerja dan Motivasi Kinerja. JRBI, 63-74.

Hair, Jr et.al. (2010). Multivariate Data Analysis (7th ed). United States : Pearson.

Kuncoro, Mudrajad. (2013). Metode Riset untuk Bisnis dan Ekonomi. Jakarta: Penerbit Erlangga. 
Pawirosumarto, Suharno., Sarjan, Purwanto Katijan., \& Gunawan, Rachmad. (2017). "The effect of work environment, leadership style, and organizational culture towards job satisfaction and its implication towards employee performance in Parador Hotels and Resorts, Indonesia”. International Journal of Law and Management, 59 (6), 1337-1358.

Siswanto, Rendyka Dio dan Djambur Hamid. (2017). Pengaruh Gaya Kepemimpinan terhadap Kinerja Karyawan (studi pada karyawan divisi Human Resources Management Compensation and Benefits PT Freeport Indonesia). Jurnal Administrasi Bisnis, 42 (1), 189-198.

Sugiyono. (2008). Metode Penelitian Bisnis. Edisi ke 12. Bandung: Alfabeta.

Triton. (2006). SPSS 13.0 terapan : Riset Statistik Parametrik. Yogyakarta : Andi.

Wardani, Rodiathul Kusuma., Mukzam, M. Djudi., dan Mayowan, Yuniadi. (2016). Pengaruh Budaya Organisasi terhadap Kinerja Karyawan. Jurnal Administrasi Bisnis, 31 (1), 5865. 